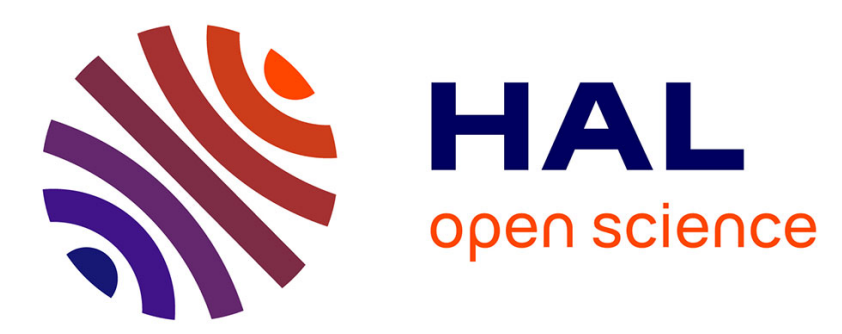

\title{
End-of-range defects in germanium and their role in boron deactivation
}

\author{
F. Panciera, P F Fazzini, M. Collet, J. Boucher, Eléna Bedel-Pereira, Fuccio \\ Cristiano
}

\section{- To cite this version:}

F. Panciera, P F Fazzini, M. Collet, J. Boucher, Eléna Bedel-Pereira, et al.. End-of-range defects in germanium and their role in boron deactivation. Applied Physics Letters, 2010, 97 (1), pp.012105. 10.1063/1.3456537 . hal-01922899

\section{HAL Id: hal-01922899 \\ https://hal.science/hal-01922899}

Submitted on 14 Nov 2018

HAL is a multi-disciplinary open access archive for the deposit and dissemination of scientific research documents, whether they are published or not. The documents may come from teaching and research institutions in France or abroad, or from public or private research centers.
L'archive ouverte pluridisciplinaire HAL, est destinée au dépôt et à la diffusion de documents scientifiques de niveau recherche, publiés ou non, émanant des établissements d'enseignement et de recherche français ou étrangers, des laboratoires publics ou privés. 


\title{
End-of-range defects in germanium and their role in boron deactivation
}

\author{
F. Panciera, ${ }^{\text {a) }}$ P. F. Fazzini, M. Collet, J. Boucher, E. Bedel, and F. Cristiano \\ LAAS, CNRS, 7 Avenue du Colonel Roche, 31077 Toulouse, France and UPS, INSA, INP, ISAE, LAAS, \\ Université de Toulouse, 31077 Toulouse, France
}

(Received 25 May 2010; accepted 31 May 2010; published online 7 July 2010)

\begin{abstract}
We investigated the thermal evolution of end-of-range (EOR) defects in germanium and their impact on junction thermal stability. After solid-phase epitaxial regrowth of a preamorphized germanium layer, EOR defects exhibiting dislocation loop-like contrast behavior are present. These defects disappear during thermal annealing at $400{ }^{\circ} \mathrm{C}$, while boron electrical deactivation occurs. After the whole defect population vanishes, boron reactivation is observed. These results indicate that germanium self-interstitials, released by EOR defects, are the cause of B deactivation. Unlike in Si, the whole deactivation/reactivation cycle in Ge is found to take place while the maximum active B concentration exceeds its solubility limit. () 2010 American Institute of Physics.
\end{abstract}

[doi:10.1063/1.3456537]

Recently, germanium is gaining a renewed interest as substitute of $\mathrm{Si}$ for microelectronic applications thanks to its attractive properties. Indeed, compared to silicon, germanium exhibits a four times higher hole mobility ${ }^{1}$ and requires lower process temperatures, ${ }^{2}$ reducing the problems related to the diffusion/activation of dopants in ultrashallow junctions and making germanium significantly better suited for integration with high-k dielectrics and metal gates. ${ }^{3}$

In Si-based devices, preamorphization followed by solid phase epitaxial regrowth (SPER) is used to achieve high dopant activation. During such process, end-of-range (EOR) defects form just below the original amorphous/crystalline $(\mathrm{a} / \mathrm{c})$ interface. Upon subsequent annealing, these defects act as a source of free Si interstitial atoms (hereafter called interstitials) that are the cause of undesirable effects on dopant behavior, such as transient enhanced diffusion (TED) and electrical deactivation. ${ }^{4,5}$

In germanium, the role of $\mathrm{Ge}$ interstitials during boron diffusion has been the object of a strong debate during the past years, and only very recently a direct experimental proof of boron TED was provided. ${ }^{6}$ On the contrary, a full experimental evidence of extended defects formation and evolution in Ge is still lacking, while no evidence at all exists concerning defects-related dopant electrical deactivation. First investigations on EOR defects in germanium, performed using transmission electron microscopy (TEM) did not reveal the presence of defects after SPER of amorphous Ge. ${ }^{7-9}$ In a more recent paper, ${ }^{10}$ EOR defects were observed only in cross section TEM (XTEM) together with several other defects caused by the incomplete amorphization achieved at high ion implantation energy $(1 \mathrm{MeV})$; a second paper ${ }^{11}$ showed a clear XTEM image of Ge EORs generated by $\mathrm{Ge}^{+}$ implantation, but surprisingly the reported plan-view (PV) TEM images were from $\mathrm{P}^{+}$amorphized specimens. In fact, following such an implant, $\mathrm{P}^{+}$-induced defects were not found by the same authors to be located just below the original $\mathrm{a} / \mathrm{c}$ interface, as in the case of a $\mathrm{Ge}^{+}$implant but were distributed over a much wider layer (down to about twice the $\mathrm{a} / \mathrm{c}$ interface depth). ${ }^{12}$ Moreover, under similar implant and

\footnotetext{
${ }^{\text {a) }}$ Present address: Now at IM2NP, case 142 Faculté Saint Jérôme 13397 Marseille, cedex 20, France. Electronic mail: federico.panciera@im2np.fr.
}

annealing conditions, $\mathrm{P}$ is known to precipitate into well visible clusters. ${ }^{9}$ Finally, a quantitative TEM study (in cross section specimens), conducted by Hickey et al. ${ }^{13}$ on a defect population produced by a nonamorphizing implant shows defects in germanium having an average size of about 10-15 $\mathrm{nm}$ that do not change in size during thermal annealing until complete defect dissolution at $750{ }^{\circ} \mathrm{C}$.

In this paper, we will first show that EOR defects in Ge can be observed both in XTEM and PVTEM and give information on their nature and thermal evolution. Then, we will provide an experimental evidence of the correlation between $B$ deactivation/reactivation and defect thermal evolution and discuss the main features of the observed phenomenon with respect to what is known in silicon.

The germanium substrate materials used in this study were of $\langle 100\rangle$ orientation, $n$ type (Sb doped) with a background concentration of $2 \times 10^{17} \mathrm{~cm}^{-3}$. Preamorphization was done using $\mathrm{Ge}^{+}$ions $100 \mathrm{keV}, 1 \times 10^{15} \mathrm{~cm}^{-2}$ to obtain an amorphous layer of $\sim 100 \mathrm{~nm}$ in agreement with the critical damage energy density model adapted to germanium by Koffel et al. ${ }^{14}$ Following the preamorphizing implant, boron was implanted to a dose of $1 \times 10^{15} \mathrm{~cm}^{-2}$ with an energy of $10 \mathrm{keV}$. To prevent possible germanium oxidation and outdiffusion, a cap of $200 \mathrm{~nm}$ of $\mathrm{SiO}_{2}$ was deposited via plasmaenhanced chemical vapor deposition prior to thermal process. Rapid thermal anneaning (RTA) was then performed in a $\mathrm{N}_{2}$ ambient with a ramp-up rate of $10{ }^{\circ} \mathrm{C} / \mathrm{s}$, at peak temperatures ranging from 400 to $900{ }^{\circ} \mathrm{C}$ for annealing times from $100 \mathrm{~s}$ to $3 \mathrm{~h}$, to complete SPER and to activate dopants.

Chemical profiles were studied by secondary ion mass spectrometry (SIMS), using a CAMECA IMS-6f instrument, by collecting $\mathrm{B}^{+}$secondary ions while sputtering with a $3 \mathrm{keV} \mathrm{O}_{2}{ }^{+}$beam. Hall effect measurement by HL5500PC Hall-van der Pauw system was performed for sheet resistance $\left(\mathrm{R}_{\mathrm{s}}\right)$, active dose $(\mathrm{N})$, and drift mobility $\left(\mu_{\mathrm{d}}\right)$ measurements. Samples were patterned with a "Greek cross" by photolithographic definition and plasma etching to ensure the confinement of the electric field lines. In this configuration, we estimate a 3\% error for directly measured quantities $\left(\mathrm{R}_{\mathrm{S}}\right.$ and $\left.\mathrm{N}\right)$ and $6 \%$ for drift mobility calculated as $\mu_{\mathrm{d}}=1 /\left(\mathrm{eN} \times \mathrm{R}_{\mathrm{s}}\right)$. 

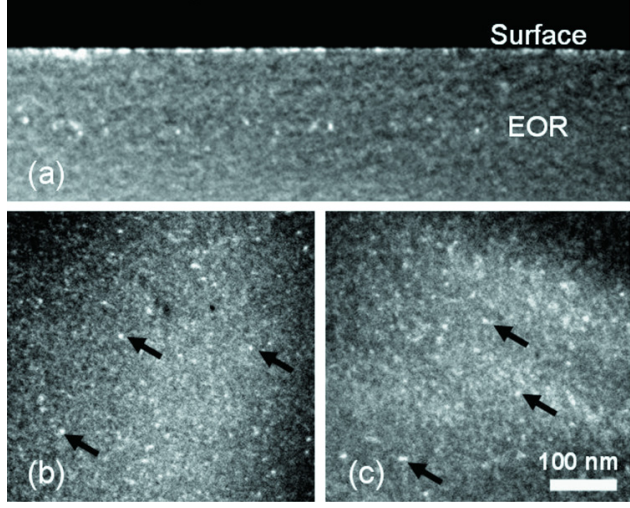

FIG. 1. (Color online) WBDF-TEM images of a Ge sample amorphized by $100 \mathrm{KeV} \mathrm{Ge}^{+} 1 \times 10^{15} \mathrm{~cm}^{-2}$ and subsequently annealed at $400{ }^{\circ} \mathrm{C}$ for $100 \mathrm{~s}$ taken in (a) cross-section using $g=422$, (b) PV under $g=400$, and (c) PV under $g=422$.

Finally, TEM was used to investigate defects in the EOR region. TEM specimens for (PV) and cross-sectional (X) observations were prepared by mechanical thinning and ion milling, performed employing low ion energy in order to avoid specimen heating. Samples were imaged using a JEOL 2010 microscope under weak beam dark field (WBDF) conditions using different diffraction vectors, $\mathbf{g}$.

Figure 1(a) shows a XTEM image $(\mathbf{g}=422)$ of a sample submitted to annealing at $400{ }^{\circ} \mathrm{C}$ for $100 \mathrm{~s}$. Following this annealing, the amorphous Ge layer is completely recrystallized and a band of defects is clearly visible at a $\sim 100 \mathrm{~nm}$ depth from the surface. This depth is compatible with the expected position of the $\mathrm{a} / \mathrm{c}$ interface. Under WBDF imaging conditions, defects appear as white dots on a dark background. The observed defect size is $\sim 6 \mathrm{~nm}$. Such a small size does not allow a direct determination of the defect nature (dislocation loops or $\{311\} \mathrm{s}$ ), however this can be achieved thanks to quantitative analysis of PVTEM images, taken under different conditions. In fact, the contrast intensity, I, of a given defect is proportional to the scalar product of the diffraction vector $\mathbf{g}$ and the defect Burgers vector $\mathbf{b}$, $(\mathrm{I} \sim \mathbf{g} \cdot \mathbf{b})$. Considering that each defect type exists in several differently oriented variants, the apparent defect density is expected to vary depending on the diffracting vector used for the TEM images. For instance, the ratio between the density of visible $\{311\}$ defects under $\mathbf{g}=\langle 422\rangle$ and $\mathbf{g}=\langle 400\rangle$, is $\sim 3$, while for dislocation loops is very close to unity. Densities of visible defects in the two imaging conditions showed in Fig. 1 (b) $(g=422)$ and Fig. 1(c) $(g=400)$ are substantially identical (around $1 \times 10^{11} \mathrm{~cm}^{-2}$ ), therefore suggesting that the observed defects are not $\{311\}$ s, but small dislocation loops. Taking an average radius of $3 \mathrm{~nm}$, the total dose of Ge interstitials trapped in the defects results approximately equal to $5 \times 10^{13} \mathrm{~cm}^{-2}$ in this sample.

In order to investigate defect thermal evolution, PVTEM were finally performed on samples submitted to longer annealing times (900 and 2700 s) or higher temperature $\left(450{ }^{\circ} \mathrm{C}\right.$ for $\left.100 \mathrm{~s}\right)$; at $400{ }^{\circ} \mathrm{C}$, defects do not change in size up to $900 \mathrm{~s}$ anneal and rapidly dissolve after longer times; at $450{ }^{\circ} \mathrm{C}$, they are already completely dissolved after $100 \mathrm{~s}$ (not shown). As already evidenced by Hickey et al. ${ }^{13}$ in the case of nonamorphizing implants, our results indicate that EOR defects in Ge exhibit a very weak size evolution during thermal processes.

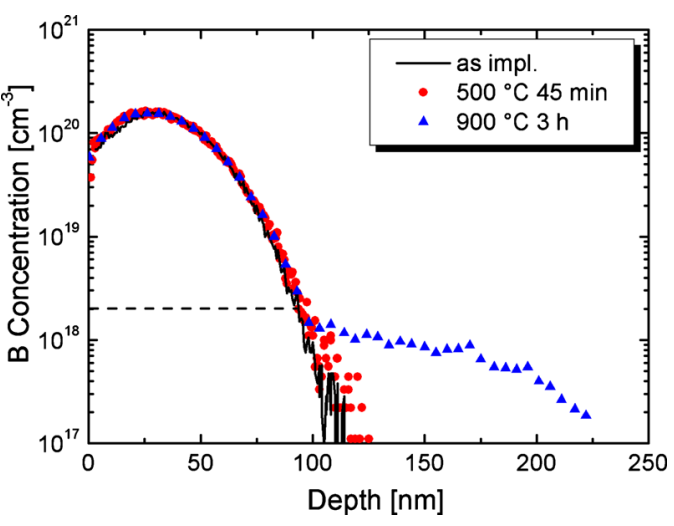

FIG. 2. (Color online) SIMS profiles of boron atoms implanted into preamorphized germanium (amorphization: $100 \mathrm{keV} \mathrm{Ge}^{+} 1 \times 10^{15} \mathrm{~cm}^{-2}$ and boron implant: $10 \mathrm{keV}, 1 \times 10^{15} \mathrm{~cm}^{-2}$ ). The as-implanted profile (black line) is compared with those obtained after annealing at $500{ }^{\circ} \mathrm{C}$ for $45 \mathrm{~min}$ (red circles) and $900{ }^{\circ} \mathrm{C}$ for $3 \mathrm{~h}$ (blue triangles). Dotted line indicates the solid solubility of B in Ge at $875^{\circ} \mathrm{C}$ (Ref. 16).

Figure 2 shows the depth profiles of B implanted in preamorphized Ge after different annealing conditions. There is no evidence of boron diffusion during the annealing at $500{ }^{\circ} \mathrm{C}$ for $15 \mathrm{~min}$ (red circles in Fig. 2), even if, under similar conditions, Simoen et al. have observed boron TED in Ge. ${ }^{15}$ However, in that study, boron profiles were more abrupt than in our case $(4 \mathrm{~nm} / \mathrm{dec}$ and $50 \mathrm{~nm} / \mathrm{dec}$, respectively) and therefore more sensitive to weak diffusion effects. On the other hand, at an annealing temperature of $900{ }^{\circ} \mathrm{C}$, boron diffusion becomes observable, as already demonstrated in literature ${ }^{16}$ almost the totality of the boron profile is immobile and diffusion broadening occurs only for concentrations below $2 \times 10^{18} \mathrm{~cm}^{-3}$. This concentration corresponds to the maximum B solubility in Ge at high temperature, as reported in literature. ${ }^{16}$

Hall effect measurements in VDP configuration provide a measure of the sheet resistance $R_{s}$, Hall mobility $\left(\mu_{H}\right)$, and Hall dose $\left(\mathrm{N}_{\mathrm{H}}\right)$. The Hall scattering factor $\mathrm{r}_{\mathrm{H}}$ relates $\mu_{\mathrm{H}}$ and $\mathrm{N}_{\mathrm{H}}$ to the drift mobility $\mu_{\mathrm{d}}$ and the active dose $\mathrm{N}$ through the formulas $\mu_{\mathrm{d}}=\mu_{\mathrm{H}} / \mathrm{r}_{\mathrm{H}}$ and $\mathrm{N}=\mathrm{r}_{\mathrm{H}} \times \mathrm{N}_{\mathrm{H}}$. Different values for the Hall scattering factor $r_{H}$ have been proposed. ${ }^{17,18}$ Unfortunately, there is not yet a universally recognized value, however, $r_{H}$ is usually found not to deviate significantly from unity. In the following, we will therefore present the raw Hall effect data without $r_{H}$ correction. Figure 3 reports values of $\mathrm{R}_{\mathrm{S}}$ (a) and $\mathrm{N}_{\mathrm{H}}$ (b) for samples submitted to process at 400 , 450 , and $500{ }^{\circ} \mathrm{C}$ for various times. As the measured mobility remains approximately constant around $110 \mathrm{~cm}^{2} / \mathrm{V} \mathrm{s}$ for all samples (not shown), $\mathrm{R}_{\mathrm{S}}$ is inversely proportional to $\mathrm{N}_{\mathrm{H}}$. The lowest thermal budget $\left(400{ }^{\circ} \mathrm{C}\right.$ for $\left.100 \mathrm{~s}\right)$ provides a Hall dose of $8.7 \times 10^{14} \mathrm{~cm}^{-2}$, which corresponds to the total activation of the implanted boron profile. This high level of active concentration, close to $2 \times 10^{20} \mathrm{~cm}^{-3}$, has also been achieved in other works, when SPER is performed. ${ }^{7,17}$ After longer processes at $400{ }^{\circ} \mathrm{C}, \mathrm{N}_{\mathrm{H}}$ is found to decrease until it stabilizes at a value of $7.7 \times 10^{14} \mathrm{~cm}^{-2}$, indicating that $\mathrm{B}$ deactivation occurs. On the other hand, during isothermal anneals at 450 and $500{ }^{\circ} \mathrm{C}, \mathrm{N}_{\mathrm{H}}$ steadily increases, suggesting that boron atoms are reactivated in such conditions until $\mathrm{N}_{\mathrm{H}}$ reaches the initial "total" activation value $\left(8.7 \times 10^{14} \mathrm{~cm}^{-2}\right.$ after $2700 \mathrm{~s}$ at $500{ }^{\circ} \mathrm{C}$ ).

The observed deactivation/reactivation phenomenon is well known for B junctions in Si. Currently accepted 


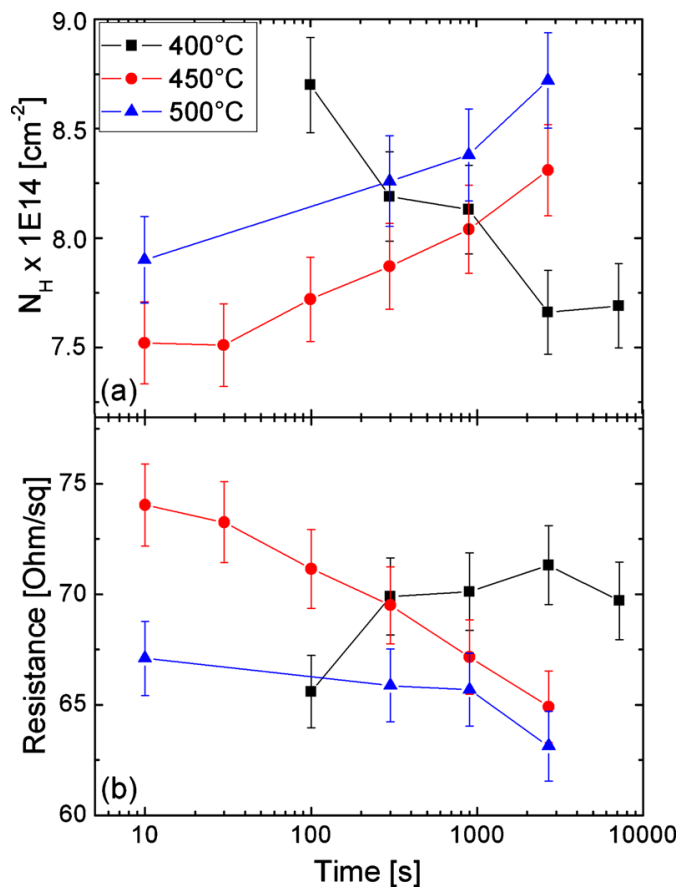

FIG. 3. (Color online) (a) Hall dose $\left(\mathrm{N}_{\mathrm{H}}\right)$ of $\mathrm{B}$ implanted (10 keV 1 $\left.\times 10^{15} \mathrm{~cm}^{-2}\right)$ in preamorphized Ge after thermal annealing at 400, 450, and $500{ }^{\circ} \mathrm{C}$. (b) Sheet resistance $\left(\mathrm{R}_{\mathrm{S}}\right)$ for the same samples.

explanations ${ }^{4,5}$ assume that dopant deactivation is due to the formation of electrically inactive boron-interstitial-clusters (BICs), caused by the migration of interstitials released from the dissolving EOR defects toward the doped region. Once the whole defect population vanishes, dissolution of BICs occurs, resulting in boron reactivation. A similar mechanism is the only satisfactory explanation of the deactivation/ reactivation phenomenon we observe in Ge. Moreover, it is strongly supported by our observations on defects evolution. Boron deactivation occurs within the same time interval necessary to achieve complete defects dissolution while the total deactivated boron dose is of the same order of magnitude $\left(\sim 1 \times 10^{14} \mathrm{~cm}^{-2}\right)$ as the density of interstitials initially trapped in the EOR defects. Finally, reactivation takes place at higher temperatures, i.e., after the total defect dissolution.

The mechanism that drives deactivation/reactivation in $\mathrm{Si}$ and in Ge appears to be the same, however, in Ge, the whole deactivation/reactivation cycle surprisingly takes place while the maximum active B concentration largely exceeds (by some decades) its solubility limit, i.e., while the system is still in a metastable state. In contrast, boron deactivation in $\mathrm{Si}$ is accompanied by a progressive decrease in the maximum active concentration down to the expected solid solubility value. ${ }^{5}$ With the aim to test the junction stability in Ge, we therefore performed annealing at $900{ }^{\circ} \mathrm{C}$ for several hours; after $3 \mathrm{~h}, \mathrm{~N}_{\mathrm{H}}$ decreases to a very low value of about $2 \times 10^{13} \mathrm{~cm}^{-2}$. This dose corresponds to an active concentration close to the boron solubility limit at this temperature $\left[2 \times 10^{18} \mathrm{~cm}^{-3}\right.$ (Ref. 16)], revealing that boron precipitated and the system reached thermal equilibrium. We therefore suggest that there are two following phases leading to boron deactivation: a first one of "transient" deactivation promoted by the excess of self-interstitial and characterized by unstable BICs formation; and a second one of precipitation during which boron definitively reaches its solubility limit. In $\mathrm{Si}$, the cycle of deactivation/reactivation is super- posed to precipitation, so when reactivation starts the system is already at equilibrium. On the contrary, in Ge these two phases occur at different times, because the thermal budget needed for the system to reach thermodynamic equilibrium, i.e., precipitation, (several hours at temperatures as high as $900{ }^{\circ} \mathrm{C}$ ), is much higher than the one required for the whole deactivation/reactivation cycle to be completed, i.e., defect and BIC dissolution $\left(\sim 15 \mathrm{~min}\right.$ at $\left.500{ }^{\circ} \mathrm{C}\right)$. This result is very interesting from a technological point of view, as it implies that, in Germanium, it is possible to achieve highly activated defect-free $\mathrm{p}^{+}-\mathrm{n}$ junctions using the preamorphization technique.

In conclusion, we investigated the thermal evolution of EOR defects in germanium and their impact on junction thermal stability. Thanks to quantitative analysis, we demonstrated that these defects are small dislocation loops. Fast defect evolution is observed at $400{ }^{\circ} \mathrm{C}$, leading to total defect dissolution after a $900 \mathrm{~s}$ annealing. We showed that a strong correlation exists between defect dissolution and boron electrical deactivation/reactivation, indicating that interstitial flux, coming from EOR region, can enhance boron deactivation at low temperatures. Unlike in $\mathrm{Si}$, the whole defect-induced deactivation/reactivation cycle in $\mathrm{Ge}$ is found to take place while the maximum active $\mathrm{B}$ concentration largely exceeds its solubility limit, explaining why it is possible to achieve, in Germanium, highly activated defect-free $\mathrm{p}^{+}-\mathrm{n}$ junctions.

The authors wish to thank the TEAM service of LAASCNRS for the technical support.

${ }^{1}$ C. Claeys and E. Simoen, Germanium-Based Technology: From Materials to Devices (Elsevier, Amsterdam, 2007).

${ }^{2}$ C. Claeys, E. Simoen, K. Opsomer, D. P. Brunco, and M. Meuris, Mater. Sci. Eng., B B154-B155, 49 (2008).

${ }^{3}$ C. O. Chui, S. Ramanathan, B. B. Triplett, P. C. McIntyre, and K. C. Saraswat, IEEE Electron Device Lett. 23, 473 (2002).

${ }^{4}$ B. J. Pawlak, R. Surdeanu, B. Colombeau, A. J. Smith, N. E. B. Cowern, R. Lindsay, W. Vandervorst, B. Brijs, O. Richard, and F. Cristiano, Appl. Phys. Lett. 84, 2055 (2004).

${ }^{5}$ F. Cristiano, N. Cherkashin, P. Calvo, Y. Lamrani, X. Hebras, A. Claverie, W. Lerch, and S. Paul, Mater. Sci. Eng., B B114-B115, 174-175 (2004).

${ }^{6}$ E. Napolitani, G. Bisognin, E. Bruno, M. Mastromatteo, G. G. Scapellato, S. Bononelli, D. De Salvador, S. Mirabella, C. Spinella, A. Carnera, and F. Priolo, Appl. Phys. Lett. 96, 201906 (2010).

${ }^{7}$ A. Satta, E. Simoen, T. Clarysse, T. Janssens, A. Benedetti, and B. D. Jaeger, Appl. Phys. Lett. 87, 172109 (2005).

${ }^{8}$ Y. L. Chao, S. Prussin, J. C. S. Woo, and R. Scholz, Appl. Phys. Lett. 87, 142102 (2005).

${ }^{9}$ A. Satta, E. Simoen, R. Duffy, T. Janssens, T. Clarysse, A Benedetti, M. Meuris, and W. Vandervorst, Appl. Phys. Lett. 88, 162118 (2006).

${ }^{10}$ D. P. Hickey, Z. L. Bryan, K. S. Jones, R. G. Elliman, and E. E. Haller, Appl. Phys. Lett. 90, 132114 (2007).

${ }^{11}$ S. Koffel, N. Cherkashin, F. Houdellier, M. J. Hytch, G. Benassayag, P. Scheiblin, and A. Claverie, J. Appl. Phys. 105, 126110 (2009).

${ }^{12}$ S. Koffel, P. Scheiblin, A. Claverie, and V. Mazzocchi, Mater. Sci. Eng., B B154-B155, 60 (2008)

${ }^{13}$ D. P. Hickey, Z. L. Bryan, K. S. Jones, R. G. Elliman, and E. E. Haller, J. Vac. Sci. Technol. B 26, 425 (2008).

${ }^{14}$ S. Koffel, A. Claverie, G. Benassayang, and P. Scheiblin, Mater. Sci. Semicond. Process. 9, 664 (2006).

${ }^{15}$ E. Simoen, G. Brouwers, A. Satta, M. L. David, F. Pailloux, B. Parmentier, T. Clarysse, J. Goossens, W. Vandervorst, and M. Meuris, Mater. Sci. Semicond. Process. 11, 368 (2008).

${ }^{16}$ S. Uppal, A. F. W. Willoughby, J. M. Bonar, N. E. B. Cowern, T. Grasby, R. J. H. Morris, and M. G. Dowsett, J. Appl. Phys. 96, 1376 (2004).

${ }^{17}$ S. Mirabella, G. Impellizzeri, A. M. Piro, E. Bruno, and M. G. Grimaldi, Appl. Phys. Lett. 92, 251909 (2008).

${ }^{18}$ M. B. Prince, Phys. Rev. 92, 681 (1953). 